\title{
A Novel Protection and Utilization Pattern for Urban Wetland-As an Example of Hemu Wetland in Hangzhou, China
}

\author{
Nongnong Shi ${ }^{* \#}$, Minger Ye $^{2 \#}$, Tongfei Lai ${ }^{1}$, Zhiming Yu${ }^{1}$, Yunli Pan ${ }^{2}$, Mengying Yu ${ }^{2}$, \\ Xiaoqi Zhou ${ }^{2}$ \\ ${ }^{1}$ School of Life and Environmental Sciences, Hangzhou Normal University, Hangzhou, China \\ ${ }^{2}$ School of Agriculture and Biological Technology, Zhejiang University, Hangzhou, China \\ Email: 867594089@qq.com
}

Received 17 February 2015; accepted 8 March 2015; published 10 March 2015

Copyright (C) 2015 by authors and Scientific Research Publishing Inc.

This work is licensed under the Creative Commons Attribution International License (CC BY). http://creativecommons.org/licenses/by/4.0/

(c) (i) Open Access

\begin{abstract}
This paper proposes an innovative plan and its implement strategy of Hemu urban wetland. The plan takes into consideration its historical background and current status, its protection significance, strategies, solutions and support conditions. It highlights the landscape characteristics of rivers and lakes, and restores its historical flood prevention functions and climate regulation for the city. Especially, this paper proposes to achieve the restoration of "Mulberry-sided Fish Pond" farming style-an important agricultural heritage created by the ancestors inside the wetland, which is a unique and creative way to use low land for ecological agriculture and cycling economy. The proposed wetland sewage treatment schemes would be of practical importance to improve and enhance the ecological environment and promote the construction of ecological civilization in the region. The "Two zones-One block and Three complexes" protection and utilization plan is reasonable and feasible. It fully presents the functions of the wetland for its production, living, life forms and ecology, and is characterized by joint protection of the wetland by original residents and social public. This will result in active, instead of passive, wetland protection, like turning a "blood transfusion protection" to "hematopoietic protection", which reflects the sustainable development. The paper offers valuable information and strategies for planning and development of urban wetland.
\end{abstract}

\section{Keywords}

Urban Wetland, Protection and Utilization, Mulberry-Sided Fish Pond Ecosystem, Two Zones-One Block and Three Complexes

\footnotetext{
${ }^{*}$ Corresponding author.

${ }^{\#}$ Co-first author.
}

How to cite this paper: Shi, N.N., Ye, M.E., Lai, T.F., Yu, Z.M., Pan, Y.L., Yu, M.Y. and Zhou, X.Q. (2015) A Novel Protection and Utilization Pattern for Urban Wetland-As an Example of Hemu Wetland in Hangzhou, China. Journal of Water Resource and Protection, 7, 300-311. http://dx.doi.org/10.4236/jwarp.2015.74024 


\section{Introduction}

Hemu wetland is located in the Wanjing Subdivision, Yuhang District in the western Hangzhou city, Zhejiang Province, China. The total area is about 8.51 square kilometers. It is adjacent to the famous Hangzhou Xixi National Wetland Park. At present, it is an undeveloped and original urban wetland [1]. Located in ancient Taihu basin, Hemu wetland is a typical plain depression in the network of rivers and ponds. In the ancient times, irrigation systems consisting of dikes and fields were constructed, where the dikes were built around the low areas to prevent flooding and protect polders, and the paddy fields surrounded by the dikes were for crop cultivation.

\subsection{Background Review of Protection and Utilization}

Along with the migrated silk weaving technology, the silk industry in the region resulted in prosperity. Ancestors creatively planted mulberry trees on the dikes, grew rice in elevated flat and fertile polders, and cultured fishes in low and swamp-like ponds. The thick and fertile sludge in the bottom of pond was dug and moved to the dikes around the ponds to fertilize mulberry trees, and the excess nutrients in the dike soil were washed down with rain and flowed into the fish ponds. Excess pupae and silkworm excrement from the sericulture was used as fish feed. These activities resulted in "Mulberry-sided Polder" and "Mulberry-sided Fish Pond" systems which fitted well with the principles of cycling economy and ecological agriculture, as well as with agricultural development of the region [2] [3]. These systems greatly promoted the development of fishery, sericulture and silk industries in the Taihu River basin and reached a peak period in the late Ming and early Qing Dynasty. The mulberry-sided fish pond system provides an example of solution to agricultural source pollution due to overuse of chemical fertilizers and pesticides. This system is a unique and creative farming style in low land use and ecological and cycling economy [4]. Therefore, for protection and utilization of the Hemu wetland, what needs to be done first is to protect and utilize the "Mulberry-sided Fish Pond" system, an important and valuable agricultural heritage created by ancestors for the wetland.

Hemu wetland is located along the northern margin of subtropical monsoon climate zone with great biological diversity. It has plants of 85 families, 182 genera and 221 species, including 207 species of angiosperm, 9 species of pteridophytes, and 5 species of gymnosperm. Plants on river banks are wingnut, willow, early bamboo, persimmon, Sapium sebiferum, Paulownia, camphor, elm, hibiscus, peach, gardenia, etc. Reed, Arundo donax and silvergrass are the common plants on the riversides. In the water Eichhornia crassipes, Alternanthera philoxeroides, lotus, water chestnut, duckweed and Acorus calamus are growing [5].

Approximately 12 orders, 26 families and 89 species of birds including herons, egrets, herons, green winged teals, spot billed duck, white-fronted Goose, kingfishers, woodpeckers, swallows, thrushes and tits, 3 orders and 6 families of mammals such as rabbits and weasels, 3 orders and 6 families of reptiles like toad, limnocharis, Rana nigromaculata, money frogs and Rana rugulosa were once observed to live in the Hemu wetland zone [6].

\subsection{Current Problems with the Wetland Protection}

Since the beginning of the 1990s, the city of Hangzhou has been expanding continuously and a lot of farmlands and wetlands have been replaced with real estate and factories. Right now, the Hemu wetland area is equivalent to only half of that original. Industrial wastewater is discharged directly to the wetland, resulting in serious pollution of rivers and lakes, and killing large amounts of aquatic organisms and accumulation of harmful substances such as heavy metals in aquatic organisms. In addition, a large number of residential housings developed in the wetland release a large volume of sewage into the wetland, leading to the eutrophication of the wetland. Sometimes, some algae proliferate explosively, heavily degrading the ecological environment of the wetland and severely damaging the biodiversity [7] [8]. According to a survey made by Ni et al. in July and November 2011 and January and April 2012, the data on average contents of ammonia nitrogen, nitrite nitrogen, nitrate nitrogen, total nitrogen, total phosphorus, chemical oxygen demand (COD), biochemical oxygen demand (BOD), chlorophyll, temperature, turbidity, dissolved oxygen, $\mathrm{pH}$, electronic conductivity (EC), oxidation and restore potential (ORP) and other indexes taken from 15 sites show that water environment quality is below the standards for agriculture and landscape in the towns inside the wetland, such as Hemu bridge, Chenjia bridge, Nanxing bridge, Shanghe road, Yujiadoumen, Jiuqu bridge, Xingfu bridge, Jiuqu bay, Dongdun pond, Xidun lock, Yanyun bridge, Wutong bridge, Xidun pond, Ruanjia farm, and Aquatic product village. The water was classified as low-grade. The monitoring results showed that $\mathrm{N}$ and $\mathrm{P}$ pollution were serious in four time periods at all sites. In addition, the water in the 
Ruanjia farm and Aquatic product village sites was most heavily polluted. This might be because they are geographically close to the Xianlin industrial zone [9].

Field investigation by the project team found that the traditional and ecological agriculture systems "Mulberrysided Polders" and "Mulberry-sided fish Ponds" in the wetland no longer existed. What left over is an extensive and unmanaged natural ecological landscape. Urban wetland is different from wetlands in remote and sparsely populated areas, because it is located in the urban areas with low position. This makes it prone to nutrient gatherings as a result of flowing of sewage and other polluted water. If there is no adjustment by artificial cycling ecological agriculture systems with high output and high nutrient consumption, and such large amount of nutrients are handled only by natural vegetation in ecological system in the urban wetland, eutrophication of water will occur easily and frequently. This will result in the degradation of the structure and functions of wetland ecosystems, and in turn further reduce the self-purification ability of water and consequently exacerbate deterioration of water quality, forming a vicious circle and eventually leading to the degradation of wetland landscape. indicate that for the urban wetland, as the city expands gradually, the sources of pollution not only continue to exist but also to expand [10] [11]. If we continue to use the protection modes for remote or sparsely populated natural wetlands for the urban wetland, it will be difficult to play its ecological functions.

A survey showed that the Wanjing village located within the jurisdiction area of the Hemu wetland was completely flooded due to Typhoon "Feite" outbreak on 7 October 2013. All the houses had the water of $1 \mathrm{~m}$ deep, and crops and fields were largely flooded. Therefore, without solid control of upstream floods and perfect drainage system of downstream floods, Hemu wetland will be flooded and its ecosystem will be severely damaged, if the wetland is managed naturally, when extreme disasters such as flooding occur [12]-[14].

\subsection{Protection and Utilization: Necessity and Significance}

Hemu wetland was historically responsible for flood discharge for the rivers between Tianmu Mountain in western Hangzhou and Dongtiao brook. In recent years, with the rapid development of the region, the functions of wetland gradually are weakening for its flood discharge. We should not only keep its beautiful landscape, but also the flood discharge function. Therefore, it is very important to figure out how to protect and enhance the flood discharge function of the Hemu wetland. This will prevent disasters resulting from extreme weather and benefit sustainable development of regional economy [15]. Historically, the "Mulberry-sided Polder" and "Mulberrysided Fish Pond" systems within the Hemu wetland were cycling ecological agriculture systems. It played an important role in maintaining good regional ecological environment within the water systems. Restoration and development of these systems will improve and enhance the regional ecological environment and promote the management of five different types of water (sewage treatment, flood control, drainage of flooded water, water supply and water saving) carried out by local government.

\subsection{The Goals of Protection, Utilization and Development}

The goals are to let the wetland play important roles in reducing river eutrophication due to city life and preventing city flooding due to extreme weather by restoration and utilization of the "Mulberry-sided Fish Pond" wetland ecosystem created by ancestors. Meanwhile, through exploration of sericulture, fish culture and already formed "sheep-pot" culture in the local region, Hemu wetland has been developed into an integrated eco-agricultural demonstration area with high productivity, technology development, scientific education, tourism and leisure, vacation and health, and cultural heritage.

\section{Protection and Utilization Plan}

\subsection{Space Layout}

We propose to have a "Two districts-One block and Three complexes" overall planning for Hemu wetland protection and utilization.

Two districts: to divide the Hemu wetland into the original ecological protection zone and the restoration protection zone (Figure 1).

One block: to construct a block possessing wetland culture.

Three complexes: to constructsericulture complex, "sheep pot" culture complex and fish culture complex. 


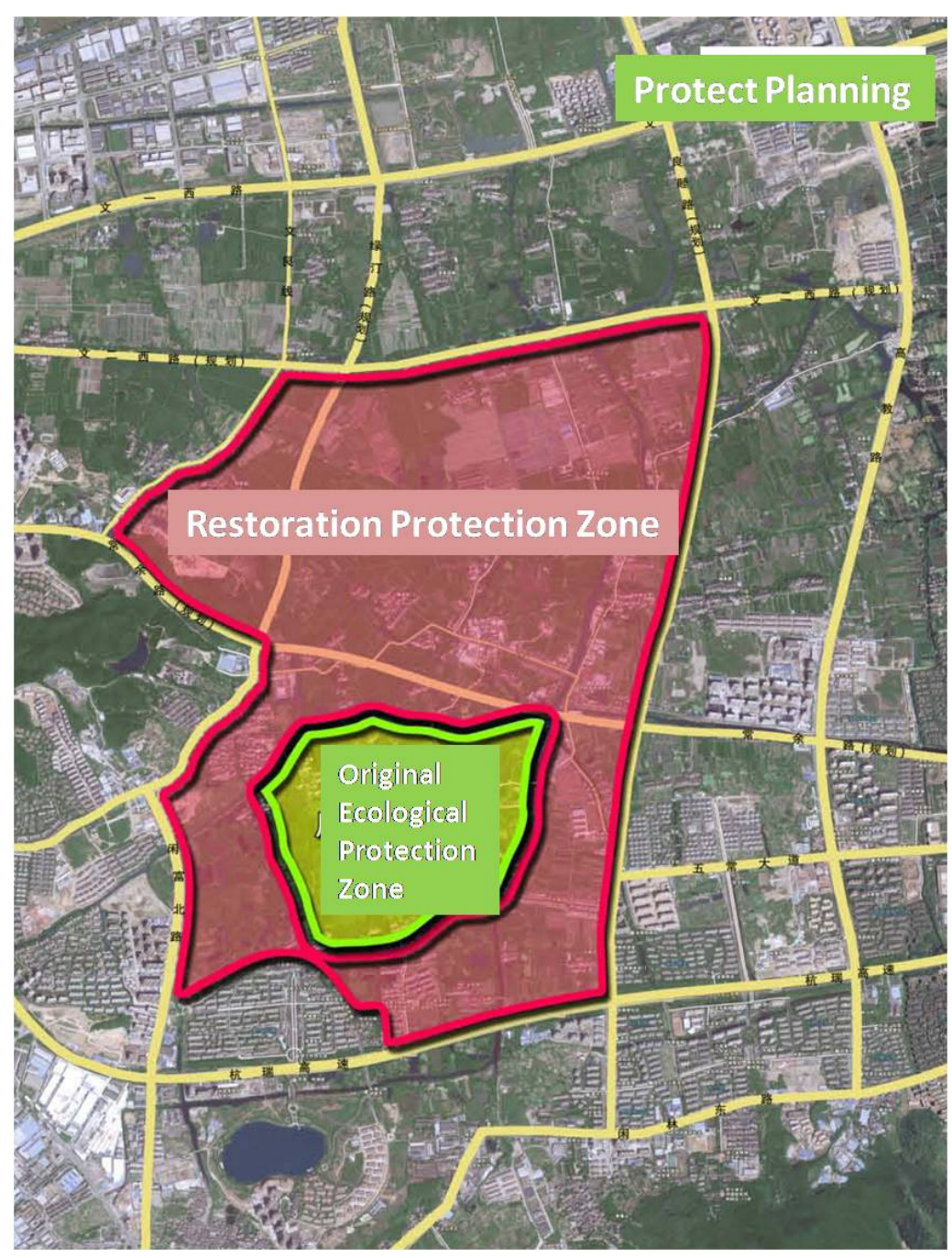

Figure 1. The original ecological protection zone and the restoration protection zone in protection planning of Hemu wetland.

\subsection{Protection Planning}

The original ecological protection zone will maintain the current wetland natural ecological landscape. At the east and west ends of the zone, there will establish two ecological isolation bands for sewage. The center original ecological protection area of the zone is the ecological wetland area for "Mulberry-sided Fish Pond" system (Figure 2).

\subsubsection{Restoration Plan for the "Mulberry-Sided Fish Pond" Ecosystem}

In the system, mud from the rivers and ponds were usually dug up and used to fertilize the mulberry trees every year, thus preventing eutrophication of rivers and ponds and elevating the dikes every year, and made the river clean and smooth. This also continuously increased the overall water storage capacity in the whole system and played important role in preventing or mitigating flood disaster.

High standard "Mulberry-sided Fish Pond" system is planned by restructuring the paddy fields and some fish ponds in the center original ecological protection area. The dike to pond ratios in the planned system will be 6:4 or 5:5 to ensure a balanced ecological system to maximize the economic and social benefits. The crops for the dike can be selected from mulberry tree, fruits, sesame, rapeseed, flowers and Bahia grass to form an interspersed, changing and beautiful landscape of the fish ponds with mulberry-, fruits-, rapeseeds-, and flowers-sided. Such landscape will be very scenic and attractive to tourists. 


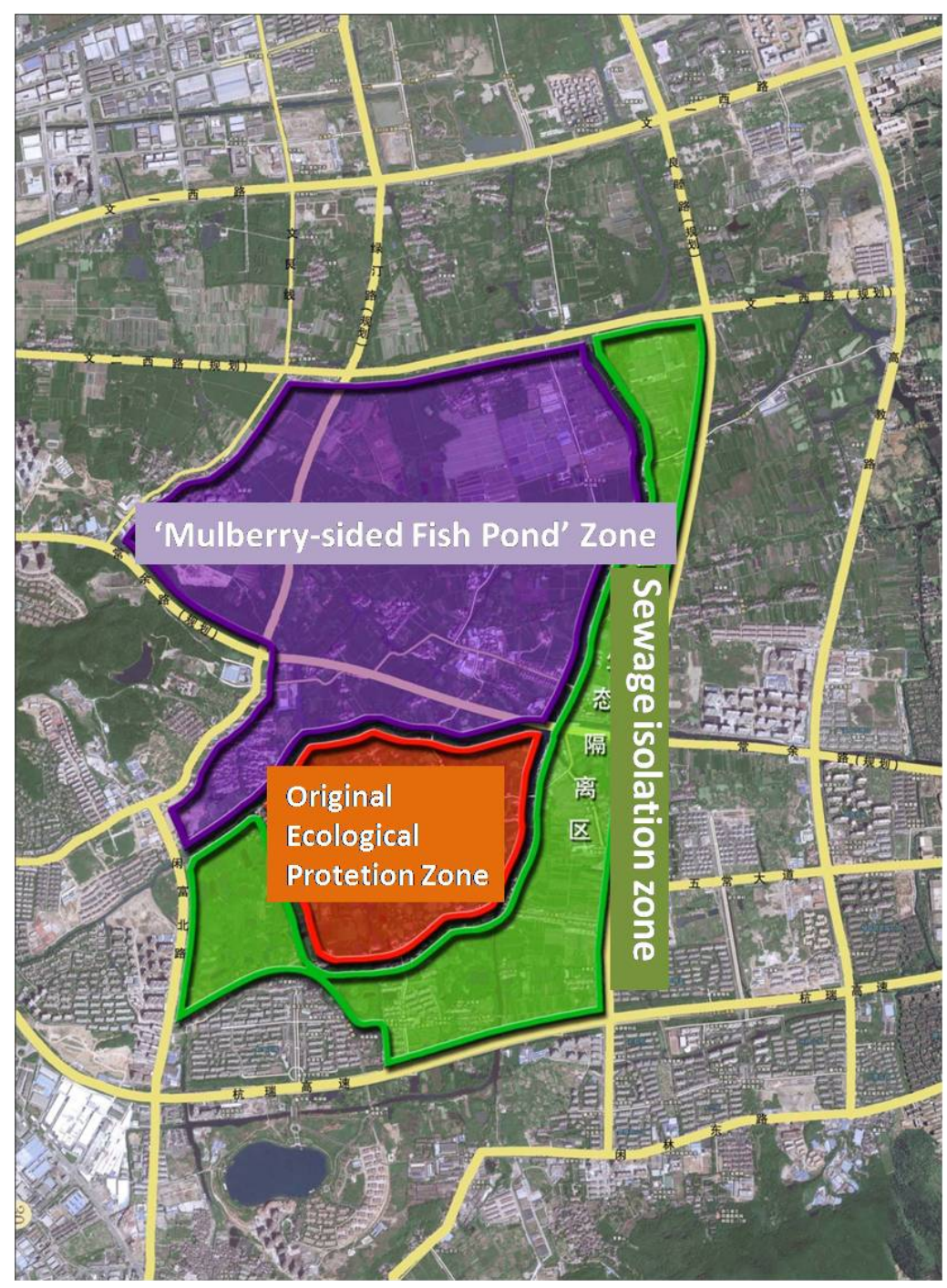

Figure 2. The "Mulberry-sided Fish Pond" area and the ecological isolation bands for sewage in protection planning.

\subsubsection{Water Purification Plan}

The following three measures are planned to purify the water in the protected areas.

1) Establishment of ecological isolation zone for sewage

At the east and west ends in southern restoration protection area, ecological isolation bands for sewage will be built to prevent the upstream polluted water from industrial parks on the Xianlin road and large residential areas from entering the center wetland area directly through the Xianlin and Wutong harbors without any purification. For better purification of the upstream polluted water, three layers of biological water purification systems including aquatic plant purification, aquatic animal purification and reed purification are planned to ensure water quality being at standard II and III before entering the protected zone.

Aquatic plant purification system: Proper deployment of floating, submerged and emergent plants in the water of the wetland ecological isolation zone and irrigation rivers will have both ornamental value and the biological purifying function. Plants of various heights can be planted beside the water for better landscape purpose, such as tall plants like reed, and middle plants like cattail and windmill grass, and short plants like arrowhead. Over the water surface, floating plants (such as eye lotus) or floating carriers (such as aquatic biological floating island, in which terrestrial flowers such as beauty banana, or water spinach, celery and other vegetables are cultured in water). These plants will reduce light flux into the lakes, inhibit the growth of phytoplankton and increase the 
transparency of water. Submerged plants (such as Vallisneria spiralis, Potamogeton, etc.) or the leaf-floating plants (such as lotus) can be planted at the bottom of the water to absorb and transform organic matters and nutrients in sediment and water. They will reduce nutrient concentration in water, inhibit the growth of phytoplankton, prevent sediment from re-suspension to increase the water transparency and generate a clean river.

Aquatic animal purification system: appropriate culture of aquatic animals can effectively remove the surplus nutrients in water. For example, mandarin fish can be raised to inhibit wild fish, resulting in increased planktonic animals and reduced phytoplankton, and improved water transparency and self-purification ability of wetland and rivers. At the same time, mussels, snails and other aquatic animals can be raised to further purify the water. Mussels can filter and consume the suspended algae and organic debris, and improve water transparency. Snails eat mainly periphyton, and secrete flocculent materials to aggregate the suspended matters in lake water, and clean up the water.

Reed purification system: In the protected area, reed water purification system should be greatly developed. With reed, the removal rate of BOD5 can be above $90 \%$, suspended solids (SS) more than 91\%, ammonia nitrogen (NHO-N) over $76 \%$, total nitrogen (T-N) over $84 \%$, total phosphorus (T-P) over $87 \%$, chlorobenzenes over $81 \%$, chlorophenols over $82 \%$, pesticides over $89 \%$, other benzenes over $95 \%$, enterovirus over $94 \%$, total bacteria above $99 \%$, worm eggs over 99\%, E. coli over 99\%, Salmonella over 99\% and bacteriophages over 99\%. Reed purification system can also maximize the absorption and adsorption of the inorganic pollutants (heavy metals) and organic matters in the sewage, thus eliminating the water pollution risks, improve and restore the natural ecological environment.

\section{2) Ecological purification system with fish pond}

Herring (150 - 200), grass carps (10 - 20), chub (bighead carps 30 - 50, silver carps 200), flat fish (50) and crucian (50) are planned to be raised in fishpond per mu, a well-controlled water system can be established. The abundant snail and silkworm excrements can be used as fish feeds, and excrements from herrings are good fertilizer for planktonic animals and plants. The plants grown on water surface can be controlled by grass carps to ensure adequate lighting for better proliferation of planktons, which in turn provide large amount of feed for chubs. The left-over from herrings will be eaten by carps, flatfishes and crucian carps to form excellent ecological food chain. This will result in balanced pond ecology and prevent the water quality from deterioration [16]. If the water quality is "cared" by the integrated biological measures, ecologically balanced water will be achievable and water quality will be well purified [17].

\section{3) River and pond dredging systems}

Dredging is planned for the rivers and ponds in the protected area every year in the winter time, particular drainage channels such as Xianlin and Wutong harbors will be built to prevent eutrophication and ensure smooth water flow.

\section{4) Establishment of a monitoring platform for regional water environment}

utomatic remote monitoring system of water quality in the protected area will be set up to provide the real- time, all dimensional monitoring of water quality to ensure that the water quality being at grade II and III standards all year around. This will be necessary for good ecological environment and biological diversity. Water sampling sites and video monitoring systems are planned for Hemu bridge, Chenjia bridge, Nanxing bridge, Shanghe road, Yujiadoumen, Jiuqu bridge, Xingfu bridge, Jiuqu bay, Dongdun pond, Xidun lock, Yanyun bridge, Wutong bridge, Xidun pond, Ruanjia farm, and Aquatic product village in the protected area. The signals will be wirelessly transmitted to water environment monitoring platform in the management center. The monitored information will include algal concentration, water turbidity, $\mathrm{pH}$, dissolved oxygen, turbidity, water temperature, electronic conductivity, concentration of potassium permanganate, total phosphorus, total nitrogen and other water quality parameters. The fully automatic and real-time monitoring system will provide early warning for water quality to ensure the excellent condition in water network.

\section{Plan for Development and Utilization}

According to the dynamic protection idea that development while protected and protection while under development [18] [19], we propose a "One block-Three complexes" overall development and utilization plan for the Hemu wetland (Figure 3).

\subsection{One Block}

A block reflecting wetland culture is planned to display the history of farming and agriculture, low-carbon life and 


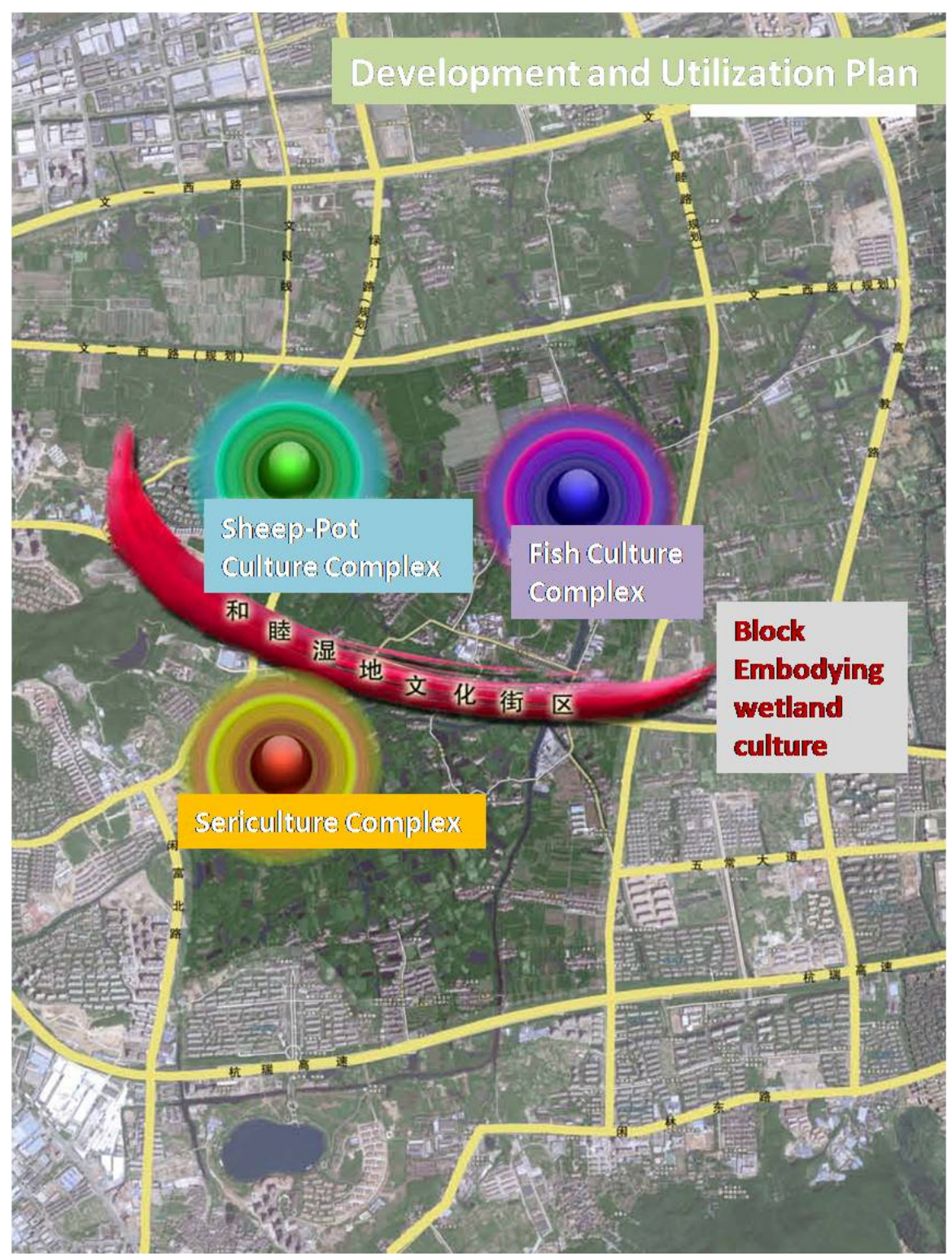

Figure 3. "One block and three complexes" for development and utilization planning.

environmental protection as the themes. This requires to fully explore the farming culture, Liangzhu culture, heritages left behind by famous ancient scholars. Exhibition halls can be set up to show farming methods, life styles and customs in history. At the same time, corresponding products of low energy consumption, low pollution, and low emission that are related to low-carbon daily life can be displayed, sold, experienced (including DIY room) along the block, such as energy-saving houses, energy-saving appliances, energy-saving building materials, environment-friendly daily necessities, and resources recycling technology and products, the solar energy technology and products, energy-saving and intelligently controlling technology and products. The consumers can learn what carbon reduction means. In addition, intangible cultural heritage products (Mulberry silk skills, Yuhang rolling lights, Wuchang dragon-boat, 18 Martial arts, Jinshan tea party et al.) and stores with a hundred year of history from local district and city (Fuyi Warehouse - selling rice; A Hundred Huichang - selling preserves; Tongfuyong - selling liquor et al.) can be actively introduced to the block in the style of traditional specific crafts shops and local snacks. This will make the block special full of farming culture with local favors, and integrated with the surrounding wetland ecological system, showing a beautiful scene of suburban in south of Yangtze River (Figure 4). 


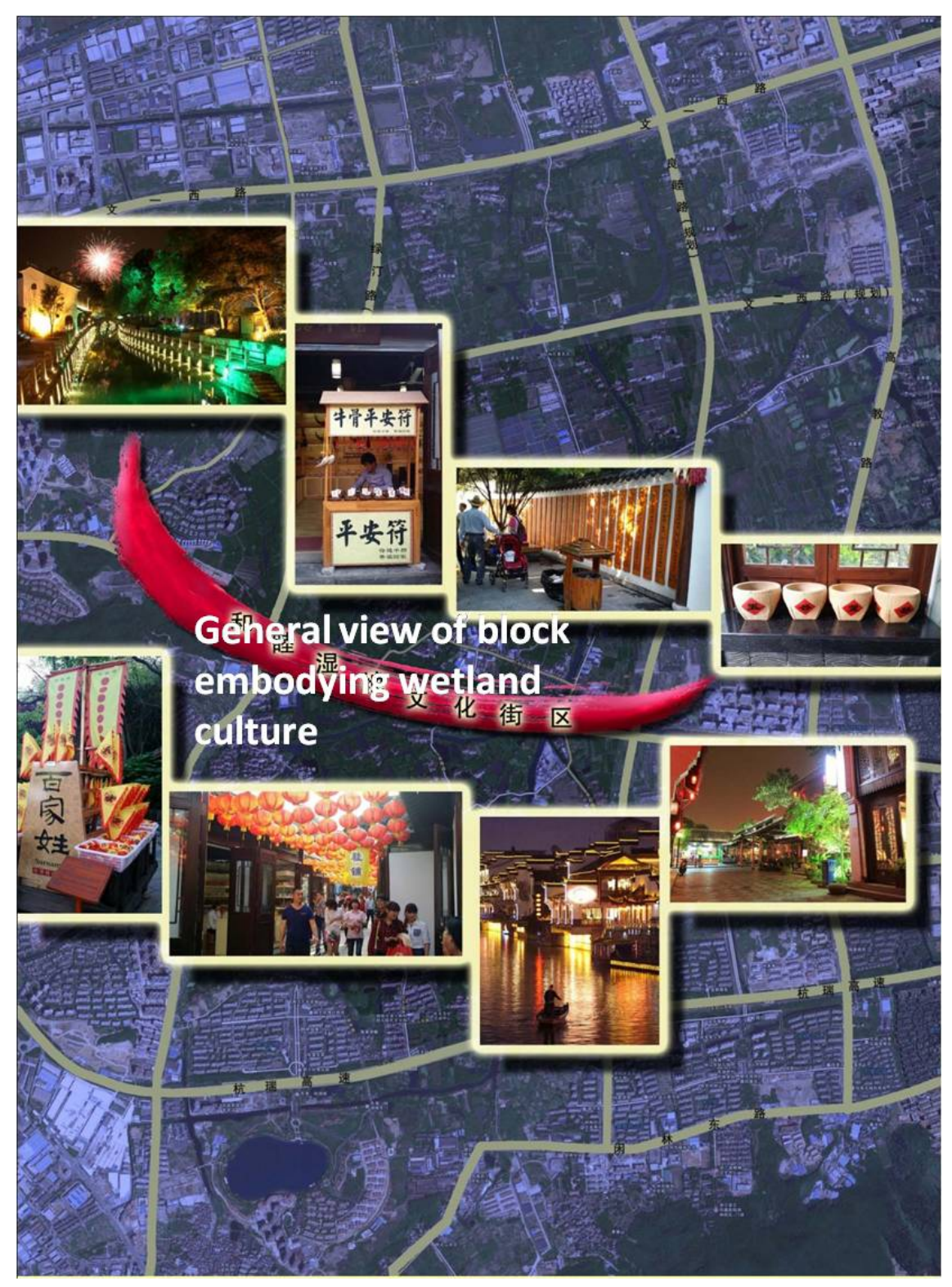

Figure 4. General view of block embodying wetland culture.

\subsection{Three Complexes}

\subsubsection{Sericulture Complex}

A sericulture museum is planned in the Wanjing village of the protected area. The museum will have exhibition halls to display the history and development of sericulture in China, using the materials and pictures to show the distribution and breeding of mulberry trees, wild silkworm and domesticated silkworm, silk reeling, and silk products. At the same time, old resident houses in the village will be rebuilt to show traditional sericulture customs including worshiping silkworm, pleasing silkworm, burning silkworm fireworks, covering silk flowers, scaring silk ghosts, burning silkworm in field, predicting silk production, and thanks for silkworm. Also planned is a "mulberry leaf tea" museum that will show products made from mulberry leaf, such as products with functions of weight reduction, beauty and blood sugar reduction. Mulberry leaf and fruit will be used to make special food products such as biscuit, noodle, cake, ice cream, steamed bun, wine, drink and jam. Beauty shops selling cosmetic products made mainly with silk fibroin as raw materials and the beauty finger gloves made of cocoons will be built to enhance the cultural taste of the village to attract tourists (Figure 5). 


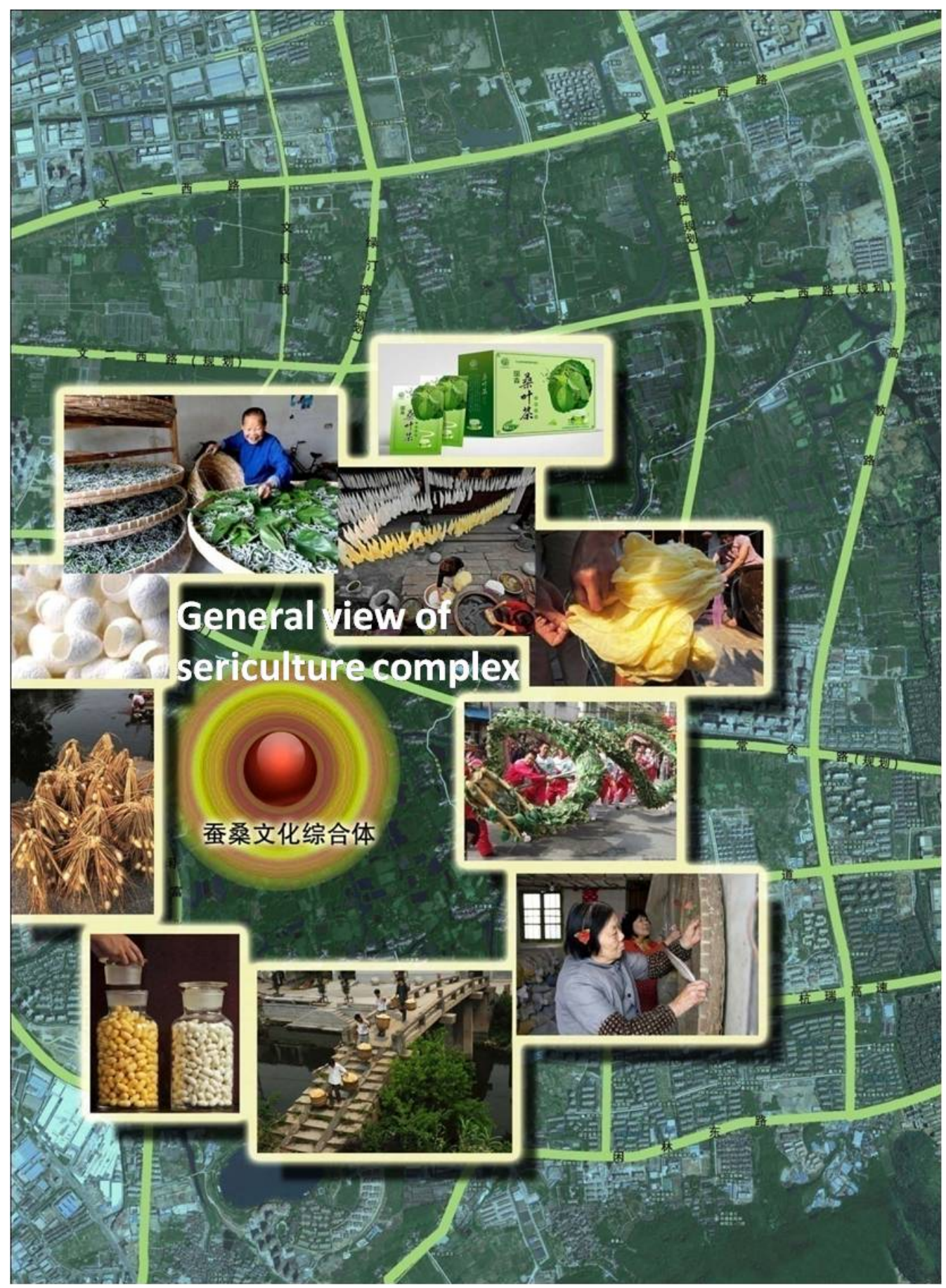

Figure 5. General view of sericulture complex.

\subsubsection{Sheep Pot Culture Complex}

The neighbor Gexiang village is planned to be the center of the traditional sheep pot food culture originated from unique folk food festival "sheep pot". The sheep culture will be investigated and explored from the aspects of history, language, diet, product, moral, etiquette, religion and aesthetic to promote the Gexiang village from "sheep pot village" to "sheep culture village". The final goal is to develop a "sheep pot culture complex" that has remarkable and regional characteristics of the Hemu wetland with its seasonal and dynamically changing wetland landscape-_"Mulberry-sided Fish Pond" (Figure 6). 


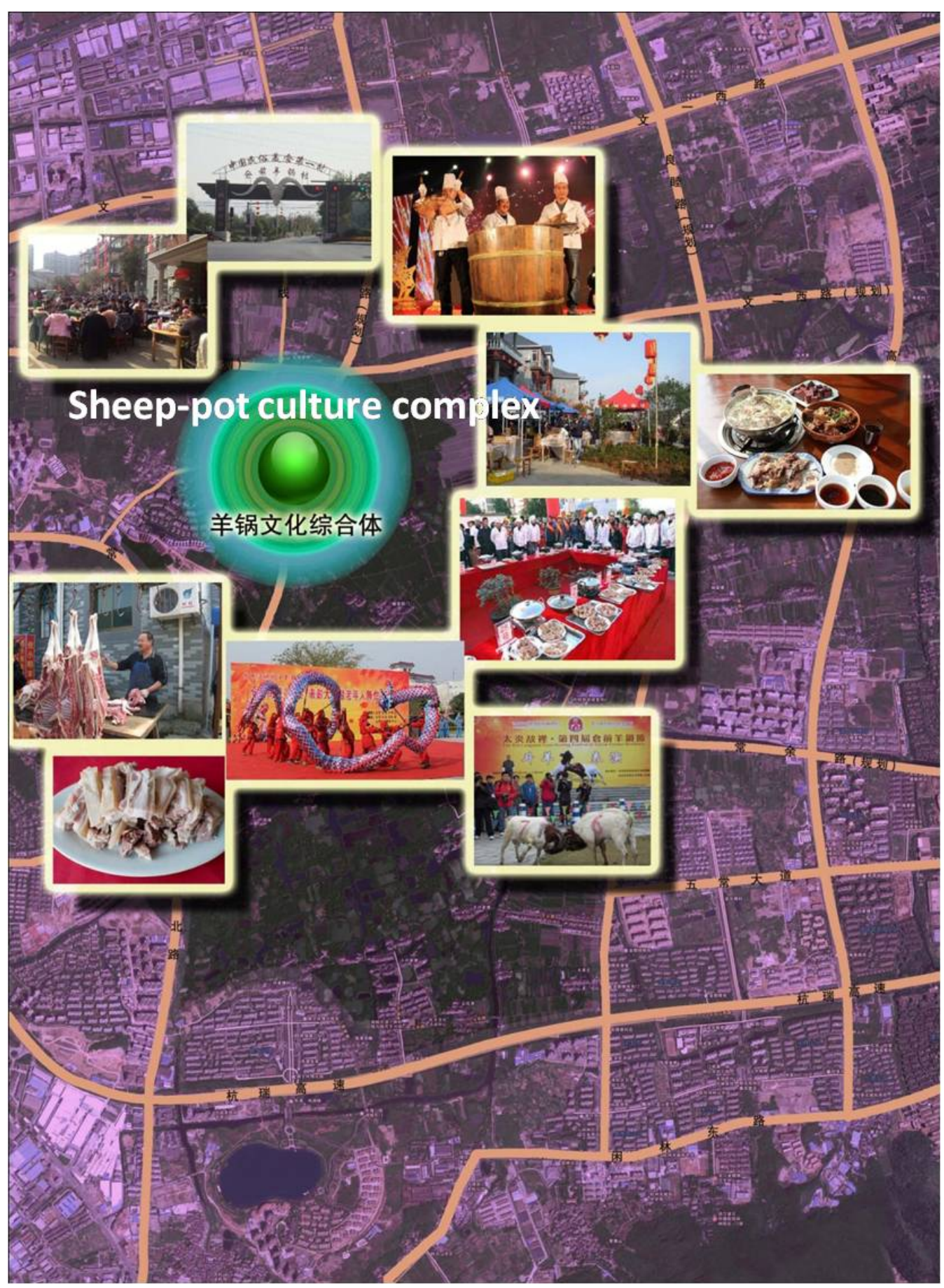

Figure 6. General view of sheep-pot culture complex.

\subsubsection{Fish Culture Complex}

A fish culture complex is planned in the "Gonglaohan" recreational fishery Park. The complex will offer unique organic fishes from the "Mulberry-sided Fish Pond" system. The complex will be used to investigate, display and explore the fishery history and development in the wetland through wetland fish species, fishing boats, fishing gear, fishing methods, aquaculture and processing technology in different periods. It will also be used to show the fishermen living habits, local customs, fish and fishermen's legends, fish-related arts, and fish cooking, derivatives from fusions of fish with religion (Figure 7). 


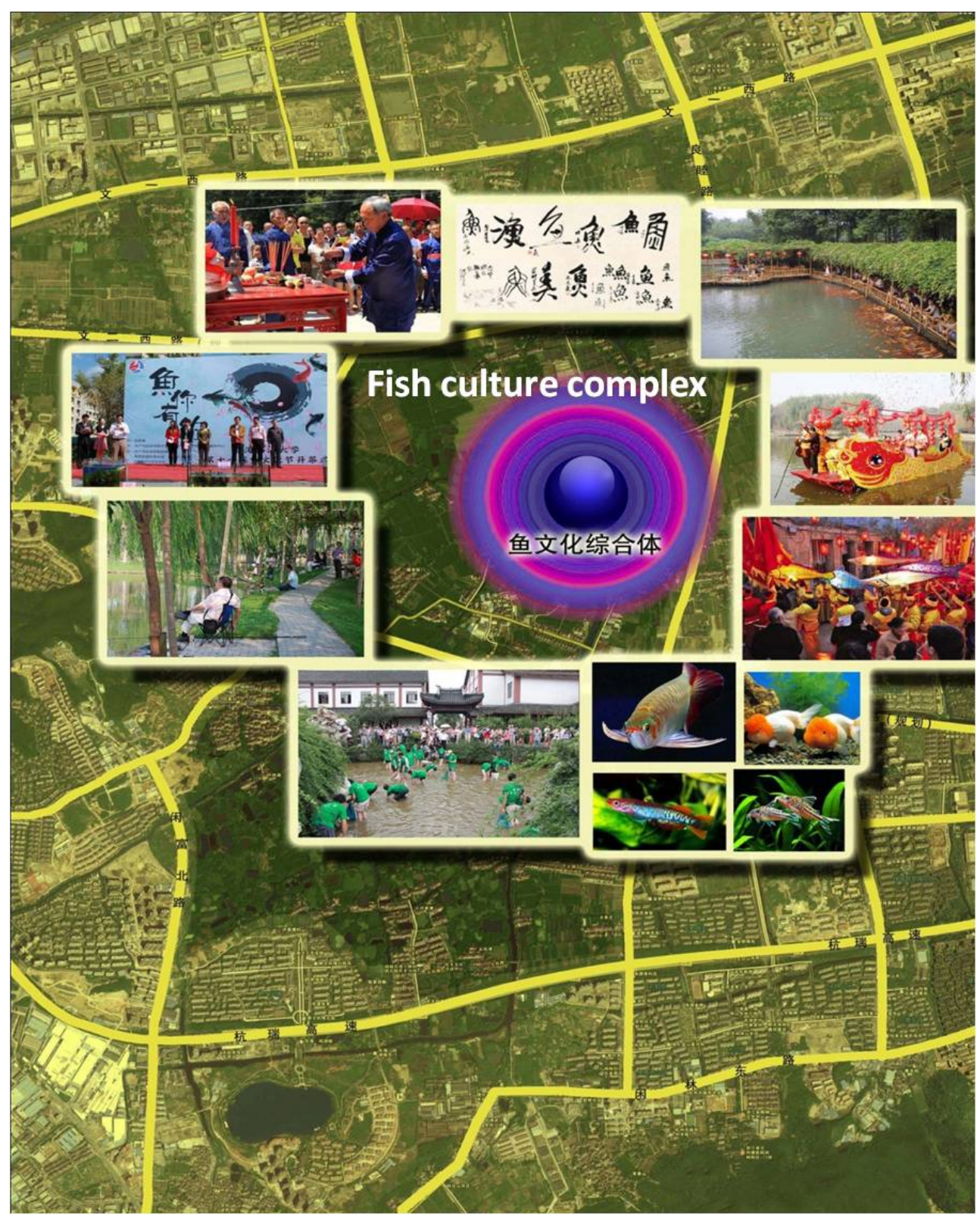

Figure 7. General view of fish culture complex.

\section{Conclusion}

Hemu wetland is low-lying in the western suburb of Hangzhou, China, which has the function of water-logging prevention in history. Mulberry-sided Fish Pond is its important agricultural cultivation pattern and landscape in ancient time. Nowadays, with the expansion of the city and the surrounding real estate development, the water quantity in Hemu wetland is decreased and it is polluted severely. Based on its background, historical function and current status, this study suggests protecting and restoring the original function and sustainable utilization of Hemu wetland by re-constructing and developing "Mulberry-sided Fish Pond" model, treating polluted river, clearing silt in order to be the restoration protection zone and original ecological protection zone, and by establishing a block area indicating local wetland culture and products, three complexes of sericulture, sheep-pot culture and fish culture. This is the novel protection and development model for urban wetland-"Two zones - One block and Three complexes" presented in this study. The results provide valuable reference in planning and utilizing urban wetland. 


\section{Acknowledgements}

This paper was funded by the branch project "Planning on Protection and Development Utilization for Hemu Wetland in Hangzhou" (2012R10039-19) of "The Program for Zhejiang Leading Team of Science \& Technology Innovation". We thank Yuhang Management Committee for offering us the Hemu Wetland CAD Blueprint; we also thank Dr. Weimin Ni in School of Life and Environmental Sciences of Hangzhou Normal University for offering us the data and information of water quality of Hemu Wetland.

\section{References}

[1] Wu, W.Z. and Fang, L. (2013) Measures of the Situation and Protection of Wetland Resources in Zhejiang Province. Zhejiang Science and Technology of Forestry, 33, 81-84.

[2] Zhou, Q. (2013) The Mulberry-Sided Fish Pond and Soil-Water Environment in the Dongtiao Downstream of Qing and Ming Dynasty. China History of Agriculture, 32, 80-90.

[3] Zhang, J., Zhong, G.F. and Wu, H.S. (1993) Analysis on Coordination Relationship of Human-Earth in Dike-Pond economic Ecosystem. Ecological Science, 12, 55-59.

[4] Ding, J.H., Wen, Y.M. and Shu, Q. (2001) Research on the Situation, Problem and Strategy for the Sustainable Development of Dike-Pond System. Environmental Sciences Chongqing, 23, 12-14.

[5] Li, Z.F., Zhang, F. and Hua, G.F. (2007) Research on Variations of Vascular Plants in Xixi Wetland of Hangzhou. Zhejiang Agricultural Sciences, 6, 655-658.

[6] Kong, Y.Y. and Xia, Y.P. (2006) Protection of Biodiversity and the Formation of Ecological Landscape in Xixi Wetland Park. Modern Gardern, 2, 11-13.

[7] Yang, L.X. (2012) Problems and Protection Measures on Urban Wetland. Forum on Science and Technology, 6, 448449.

[8] Xu, J.L. and Xu, J.L. (2011) Problems and Strategies on Wetland Protection and Management in China. Economy and Law, 4, 193-194.

[9] Ni, W.M., Zhao, L. and Hua, W.G. (2014) Analysis and Evaluation of Surface Water Quality in Hemu Wetland, Hangzhou China. Wetland Protection and Co-managing for Five Types Water, 8, 12-15.

[10] Liu, Y.J. (2013) Principles and Way to Protect Landscape of Urban Wetland. Science and Technology Wind, 7, 228232.

[11] Wang, J.N., Hu, A. and Wei, J.J. (2013) Research on Protection and Utilization Model of Urban Wetland and Compound Strategy. City Plan, 212, 137-143.

[12] Cheng, J. and Han, C. (2012) Wetland Ecological Function and Protection. Anhui Agricultural Science, 40, $9851-9854$.

[13] Hong, D.Z. (2012) Research on Management Model for the Stable Development of the Wetland Ecosystem. Innovation of Science \& Technology and Application, 7, 94.

[14] Li, J. (2012) Investigation and Analysis of the Protection of Xixi Wetland Park Hangzhou. Integrated Forum, 4, 336.

[15] Li, H.H. and Zhang, H.P. (2002) Management Mode and Evaluation for Wetland Protection Zone in China. Journal of Zhongnan Forestry College, 22, 53-56.

[16] Pu, Y.F., Zhang, F. and Yuan, W. (2006) Development Situation and Direction of Tourism Agriculture in Zhejiang Province. Zhejiang Agricultural Sciences, 6, 714-716.

[17] Wang, H. (2003) Planning and Running on Agricultural Tourism Park. China Forestry Press Inc., Beijing, 53-56.

[18] Zhao, L.X., Li, Y., Kong, F.L., Qu, L.L. and Sun, P. (2013) Research on the Development Strategy of CommunityJoint Eco-Trip in Luyang Lake Wetland. Wetland Science and Management, 9, 31-34.

[19] Wang, Y. (2010) Research on the Mechanisms of Community-Joint Eco-Trip in Wetland Development. Travel Resources, 26, 1138-1147. 